\title{
PRACTICES FOR OVERCOMING THE CHALLENGES IN E-SCM ADOPTION
}

\author{
Lidija Pulevska-Ivanovska ${ }^{1}$, \\ Sasho Josimovski, \\ Kiril Postolov, \\ University “Ss. Cyril and Methodius”, Faculty of Economics, Skopje, \\ Macedonia \\ Neda Kaleshovska, \\ VIP Operator dooel, Skopje, Macedonia
}

\begin{abstract}
The adoption of electronic supply chain management has opened new opportunities that exploit the advantages of the Internet and the new technologies. However, there are limitations in addition to the drivers for such endeavor. The goal of this paper is highlighting the challenges in e-SCM adoption and proposing practices that contribute towards overpowering these challenges to enjoy smooth and successful eSCM adoption. This paper offers deep understanding of the e-SCM concept and the opportunities that the information technologies are providing through analysis of companies that have adopted e-SCM and the benefits they have gained. This paper reviews the adoption of e-SCM through the perspective of drivers for the undertaking, challenges in the adoption and as final point it proposes practices that address these challenges and contribute in their overcoming towards successful e-SCM implementation.
\end{abstract}

Keywords: electronic supply chain management (e-SCM); information and communication technologies (ICT); benefits; drivers; challenges;

\section{INTRODUCTION}

The invisible engine today that moves the economy and the whole society at large is the Internet and the innovations in the information and communication technology (ICT) that change the way people work and live. To this extent, the advancement in the information technology, the numerous innovations, programs, software tools, means for communication etc. have led to new dimensions in the supply chain management. Poirier and Bauer (2000) have referred to this transition as a "tsunami change" representing the ability of the Internet to be an effective medium enabling integration and synchronization of all the information and processes connected to the supply chain and its management. As a result, the new concept - electronic supply chain management (e-SCM) represents the opportunities derived from the integration and synchronization of the activities, functions and applications between the partners in order that the benefits of this concept are fully exploited, suggesting the merge of the Internet with the SCM as an indispensable

\footnotetext{
${ }^{1}$ lidijap@eccf.ukim.edu.mk
} 
asset of the successful organizations. However, although there are remarkable advantages from the adoption of e-SCM and the drivers for such undertaking there are limitations that block the e-SCM adoption.

The goal of this paper is highlighting the challenges in e-SCM adoption and proposal of practices that contribute towards overpowering these challenges and thus enabling smooth and successful e-SCM adoption. We begin by explaining the concept e-SCM and studying the widespread e-SCM adoption from examples of companies that have implemented e-SCM and the benefits they have witnessed. Next, we look into more details of the adoption of e-SCM, and discuss and analyze the drivers for such undertaking. We then, look into the challenges and common obstacles to adopting e-SCM and the reasons for such result. We group these challenges into three main categories and then propose practices for overcoming these challenges addressing all barriers per category. We conclude the paper by emphasizing the findings from the research and future research directions.

\section{BASICS OF E-SCM CONCEPT}

The concept of SCM is a popular operations paradigm used by the companies as a strategic undertaking to achieve a sustainable competitive advantage. This widespread popularity has intensified furthermore with the development of information and communication technologies (ICT) that have opened the gates for integration among the supply chain partners. Such integration is essential for utilizing the advantages of SCM as it is indispensable that an organization integrates its activities both from inside and outside. This requires an integrated information system (IS) for sharing information on various value-adding activities along the supply chain. As Gunasekaren and Ngai (2004, p.270) have stated "IT is like a nerve system for SCM". Alongside, the merge of IT and SCM has led to the concept e-SCM that brings the benefits of the new technology in the practices of supply chain management.

\subsection{DEFINING E-SCM}

The demands of this day and age require that companies optimize the way they work and integrate with their partners to exploit the advantages of simultaneous optimization across all the links in the supply chain. This integration of companies is enclosed within the concept of Supply Chain Management (SCM). There are numerous definitions in the literature that help understand SCM. Mentzer et al. (2001) defined SCM as the systemic, strategic coordination of the traditional business functions 
and the tactics across these business functions within a particular organization and across businesses within the supply chain, for improving the long-term performance of the individual organization and the supply chain as a whole. Lambert et al. (1998) have defined SCM as the integration of key business processes from end user through original suppliers that provides products, services, and information that add value for customers and other stakeholders.

The technological developments in the information technologies have enabled virtual integration and coordination within the supply chain, transforming SCM into e-SCM. Lankford (2004) notes how e-SCM is a combination between the Internet and the supply chain management and the true balance between them. A more extensive definition is provided by Ross (2003) explaining how e-SCM is a concept that can be described as a network of independent partners who are not only distributers of certain products and services in the supply chain, but also stimulate the demand and lead the synchronization of capabilities and resources in the whole supply chain in order that they provide levels of operational efficiency and leadership on the market. Hence, the objective of e-SCM is to incorporate and integrate the activities across and within organizations. Such integrated supply chain involves coordination and information sharing up and down the process among all stakeholders, it enables transparency, speed in communication, data accuracy, efficiency and effectiveness which is the cornerstone for exploiting the ultimate benefits of integrated supply chain leading to opportunities for competitive advantages. The merge of these two fields, SCM and the Internet, is a key area of concern for contemporary managers and researchers (Gimenez and Lourenco, 2008) and numerous publications in prestigious academic journals can be found on this topic.

\subsection{E-SCM WIDESPREAD ADOPTION}

World class companies are accelerating their efforts to align processes and information flows throughout their entire value added network to meet the rising expectations of a demanding marketplace (Quinn, 1993). The various examples, case studies and benchmarking studies are a useful guidance and confirmation of the importance of aligning the processes and information flows throughout the supply chain to accelerate and exploit the benefits of e-SCM.

For example, General Electric's trading process network is an online business community that allows the company to transact about $\$ 1$ billion dollar worth of business with their suppliers located all over the globe. Then, three big auto makers in the US are in the process of 
launching the automotive network exchange (ANX) to further understand the impending effects of electronic business communities. ANX will establish a standard method for parts suppliers to communicate with and obtain order information from the auto manufacturers (Graham and Hardaker, 2000).

Also, Ford Motors is as successful as its ability to coordinate the efforts of its key suppliers (and its suppliers' suppliers) as steel, glass, plastic, and sophisticated electronic systems are transformed into an automobile that is intended to compete in world markets against the Japanese, the Germans, and other US manufacturers. The ability of Ford to integrate the entire supply chain has provided all partners' complete visibility to track the journey of each vehicle along the transport route via a web enabled system (Dubrin and Kirshner, 2011).

Cumberland Packaging Corporation decided to replace its 20year-old manufacturing system with a fully integrated ERP solution. After a careful evaluation, the company decided to deploy ADAGE, the powerful ERP and SCM solution from SCT Corporation. ADAGE is an object oriented, fully graphical software solution designed specifically for the process and hybrid industries. By implementing ADAGE, Cumberland has been able to reduce inventory by $10-15 \%$, or approximately $\$ 2$ million worth. In addition, the system has helped Cumberland shorten delivery lead-times, improve customer service, and better plan and forecast demand, thereby cutting production costs (Gunasekaren and Ngai, 2004).

Dell has shown great success due to the management principles and the vision Dell had about a Zero time organization built by the principles of build-to-order using the advantages of the Internet, the integrated, virtual, organization and the online sales implemented by Dell by the fall 1996. Since then, Dell has demonstrated incredible growth: a $58 \%$ revenue increase and $82 \%$ profit increase in 1997, also rise in sales to $\$ 12.3$ billion in 1997 , profits to $\$ 944$ million in 1997 and the stock split for the sixth time in 1998 (Cyberlibris.com, 1999). At the heart of the success was the ability that this strategy offered Dell exchange of inventory for information. As such, Dell uses the virtual integration model shown in Figure 1 in which traditional boundaries and roles are blurred in the value chain.

Figure 1.: Virtual Integration Model Dell

\begin{tabular}{|l|l|l|l|}
\hline Supplier & Manufacturer & & Customer \\
\hline
\end{tabular}

Source: (Cyberlibris.com, 1999) 
Saturn corporation, the subsidiary of General Motors has a separate retailer network and also no longer co-operates with a few select parts suppliers, but it finds itself partnering with many different suppliers; its in-bound logistics carrier, its out-bound carrier, and its retail dealer network, some of whom are in Japan. They all must be synchronized to deliver product that permits Saturn to compete favorably against Toyota and Honda. (Best, 1990).

Also, Wal-Mart applies state-of-the-art technology and network design that allow the company to accurately forecast demand, track and predict inventory levels, create high efficient transportation routes and manage customer relationships and service response logistics (USanFranOnline.com, 2012). This strategy has helped Wal-Mart become a dominant force in a competitive global market providing several sustainable competitive advantages, including lower product costs, reduced inventory carrying costs, improved in-store variety and selection and highly competitive pricing for the consumer.

Other well-known companies like IBM, Cisco, General Motors, Boeing and many others have integrated with their supply chain partners and have transformed their supply chain into electronic supply chain indorsing the importance of this concept.

\subsection{BENEFITS FROM E-SCM ADOPTION}

As the examples in the previous section have demonstrated, the benefits from e-SCM adoption are numerous. These companies witness enjoying the benefits such as enhanced communication, order information, complete visibility for all partners in the supply chain, reduced inventory and inventory carrying costs, shorten delivery lead times, improved customer service, better and more accurate forecast of the demand, reduced production costs, revenue and profit increase etc. As, the Internet has enabled ceaseless integration among the supply chain partners, this has opened new possibilities for competiveness of these integrated organizations.

The essence of supply chain management is as a strategic weapon to develop a sustainable competitive advantage by reducing investment without sacrificing customer satisfaction (Lee and Billington, 1992). By adopting e-business approaches the businesses can reap the benefits of supply chain integration. According to Lee and Whang (2001) the benefits from e-SCM due to the integration among the network are:

$>\quad$ Dramatic returns though efficiency improvements;

$>\quad$ Better asset utilization;

$>\quad$ Faster time to market; 
Lidija Pulevska-Ivanovska, Sasho Josimovski, Kiril Postolov, Neda Kaleshovska

$>\quad$ Reduction in total order fulfillment times;

$>\quad$ Enhanced customer service and responsiveness;

$>\quad$ Penetrating new markets;

$>\quad$ Higher return on assets;

$>\quad$ Higher shareholder value.

An important advantage from the adoption of e-SCM is the improved information management in the supply chain, enabling enhanced cooperation and information sharing. As such, companies are increasingly dependent on collaborative business processes where effective information sharing is an important success criterion (McLaren et al., 2004). This collaboration and information sharing successively leads to an improvement in data mining, and more accurate forecasting and planning, thus avoiding the common inventory problem of stock out and stock over. Commonly known as knowledge sharing, the Internet enables supply chain partners to make and access data analysis and modeling and thus make better planning and decision making (Ngai and Chan, 2002). Communication is another important asset that the e-SCM fulfills as it enables increased richness of communication through greater interactivity between the company and the customer (Watson et al, 1998).

Furthermore, according to an Accenture survey in March 2002 on the impact of SCM and the Internet, these initiatives were credited with cost reductions, improved efficiencies, better customer service, more revenues and greater competiveness by over $80 \%$ of the companies responding. Also, more than $70 \%$ felt that the application of e-based applications providing end-to-end visibility to the supply chain were the single most important enabler of collaboration with top trading partners. While the survey indicated that the prime reason why companies increasingly were turning towards supply chain partners to outsource functions was to cut costs in the short run, $70 \%$ of executives saw the long term creation of partnering agreements as a major strategy in achieving corporate objectives (Accenture, 2002).

\section{ADOPTION OF E-SCM}

The SCM is an increasingly applied operations paradigm for enhancing overall organizational competiveness. A recent survey of more than 300 supply chain-relate executives found that $92 \%$ of those surveyed were planning to implement one or more supply chain initiatives in 1999 (Bradley 1999).

Looking through the examples from the widespread adoption of eSCM, the success that these companies have accomplished and the strategic possibilities that e-SCM promises, the benefits like inventory 
reduction, efficiency, visibility etc. prove the strategic importance of eSCM adoption. However, despite these benefits, organizations that partner in strategic supply chains continue to encounter barriers and challenges on the road of implementation. Therefore, this paper focuses on the analysis on one hand side on the drivers for e-SCM adoption, but also, on the other hand side on the challenges limiting the successful eSCM realization. Also, it looks through solutions, strategies and propositions to avoid or remedy the barriers and limitations to strategic supply chain management success.

\subsection{DRVIERS FOR ADOPTING E-SCM}

The drive and incentive for e-SCM adoption derives on one hand side from the external pressures and competitive rivalry and on the other hand side from the benefits that this adoption brings. Nowadays, the global marketplace, and the competitive rivalry have led organizations in search for ways to stay competitive, to improve the agility level as well as the level of flexibility and responsiveness, leading to adoption of ebusiness solutions such as e-SCM. External pressures include such forces as advances in technology and increased customer demand across national borders (Mehta, 2004); maintaining lowers costs while meeting these divers needs (Cook and Garver, 2002) and intensified competition, all shifting the pressure towards collaboration and integration in the supply chains. The second main driving force entails the potential benefits from successful supply chain collaboration (Balsmeier and Voisin, 1996). Therefore, the benefits like cost reductions, decreased order cycle time, visibility, flexibility, richness of communication, real time information etc. all contribute as benefit triggers for e-SCM adoption.

According to a research from Speakman et al. (1998) focusing on a number of factors related to supply chain management the following reasons presented in Table 1 are indicated as top ten reasons to engage in integrated supply chain management.

All these as well as the numerous benefits identified in the previous section incentivize the companies interested in e-SCM adoption towards acceptance and realization of this supply chain transition. 
Lidija Pulevska-Ivanovska, Sasho Josimovski, Kiril Postolov, Neda Kaleshovska

Table 1.: Reasons to engage in integrated supply chain management

\begin{tabular}{|l|c|}
\hline \multicolumn{1}{|c|}{ Item description } & $\begin{array}{c}\text { Sample } \\
\text { mean } \\
\mathbf{N = 1 3 2}\end{array}$ \\
\hline 1) Increased end-customer satisfaction & 5.78 \\
\hline 2) Improved profits & 5.60 \\
\hline $\begin{array}{l}\text { 3) Secure reliable source/market for } \\
\text { this item }\end{array}$ & 5.59 \\
\hline 4) Satisfy supplier/customer request & 5.56 \\
\hline 5) Reduce overall operating costs & 5.51 \\
\hline 6) Gain strategic market position & 5.49 \\
\hline 7) Reduce lead time & 5.40 \\
\hline 8) Price paid for item class & 5.37 \\
\hline 9) Improved productivity & 5.33 \\
\hline 10) Increase margins & 5.30 \\
\hline
\end{tabular}

Source: Spekman, E.R., Kamauff JR., W.J., Myhr, N. (1998): An empirical investigation into supply chain management, International Journal of Physical

Distribution \& Logistics Management, Vo. 28, No. 8, pp.630-650.

\subsection{CHALLENGES IN ADOPTING E-SCM}

In spite the obvious benefits from the adoption and the external factors that further the need for e-SCM implementation and realization, there are also numerous challenges that these companies are encountering. The following are some of the problems and issues often cited in the literature both by researchers and practitioners when developing an ITintegrated SCM:

$>\quad$ lack of proper strategic planning;

$>\quad$ lack of integration between IT and business model;

$>\quad$ poor IT infrastructure,

$>\quad$ insufficient application of IT in virtual enterprise;

$>\quad$ inadequate implementation knowledge of IT in SCM;

$>\quad$ lack of integration of partners/suppliers and IT;

$>\quad$ lack of partners trust;

$>\quad$ lack of collaboration among partners;

$>\quad$ lack of integration of business processes.

In this paper, we synthesize the challenges in adopting e-SCM in three categories:

1) lack of strategic planning and management support;

2) inadequate or incompatible IT systems;

3) Human factor as inhibitor. 
Strategic planning and management support plays a vital role in every e-business adoption as such undertaking demands high management involvement both in terms of alignment with the company's strategy, but also in terms of management support throughout the project realization and implementation as management acceptance and support translates into people's acceptance and support in the new technology and its use. Nevertheless, implementation issues are also a significant factor in achieving the full potential of IT in SCM as inadequate or incompatible information systems are a critical limitation factor that can result in incorrect data, incorrect forecasts and demand predictions, etc. Finally, the human factor in terms of resistance to change, resistance to commitment, insufficient understanding, unclear vision etc. all play a vital role in successful e-SCM adoption and usage. "Despite years of process breakthroughs and elegant technology solutions, an agile, adaptive supply chain remains an elusive goal. Maybe, it's the people who are getting in the way?" (Beth et al., 2003, p.64)

\subsection{OVERCOMING CHALLENGES IN E-SCM ADOPTION}

The challenges identified can cost the company e-SCM implementation failure or successful project implementation, but leave eSCM as a tool that is neither used, not accepted in the company and among the partners. Therefore, strategies and solutions to avoid or mitigate these risks are essential to strategic supply chain success. As we have grouped the challenges into three categories, we continue presenting the practices for overcoming these challenges in the same analogy.

\section{A. Strategic planning and management support}

The strategic planning is a critical task for IT-enabled SCM as such endeavor has long-term implications on the performance of IT in SCM systems as well as long term performance of the company and success it accomplishes. Adopting e-SCM is a topic that deems top management attention and involvement. It requires top management consideration of both external and internal factors to an organization and proper strategy planning in these regards. Strategic planning of IT should support the long-term objectives and goals of the company and adapt the SCM plan both in terms of flexibility and responsiveness to changing market requirements. The management should consider and evaluate the skills, expertise and capabilities of the companies they are engaging collaboration and partnering with, forging close relationship with the suppliers in building a sustainable competitive network. A sustainable supply chain strategy extends these linkages upstream and down 
(Biemans and Brand, 1995) as an integrated supply chain management is an important asset in building close relationship on one hand side with the customers and on the other hand side with the suppliers.

Supply chain strategy development should be part of the business unit planning process which includes efforts aimed at developing and maintaining global information systems, addressing strategic aspects of make-or-buy issues, and accessing and managing innovation with the purpose of protecting and enhancing core technologies (Prahalad and Hamel, 1990).

Furthermore, the adoption of e-SCM requires a project management approach with the right team for the planning and implementation of IT projects. Here, the support of top management plays an essential role in providing moral support as well as financial and technical support for the implementation of IT in achieving e-SCM.

\section{B. IT system implementation and integration}

Companies need to invest large amount of money for redesigning internal organizational and technical processes, changing traditional and fundamental product distribution channels and customer service procedure and training staff to achieve IT-enabled supply chain (Motwani et al., 2000). Besides, business process reengineering has been considered as one of the most important strategies for streamlining the business process, because the effectiveness and efficiency of the supply chain processes depends on the proper coordination across the various functions. IT is an important component of reengineering business process by eliminating non-value-added activities in a supply chain. To these regards, business processes reengineering and IT compliment each other in their efforts to achieve dramatic improvements by radical changes. IT plays an important role in business process redesigning as the speed, information processing capabilities and connectivity of computers can increase the efficiency of business processes and communications in the SCM systems.

Companies suffer without having sufficient knowledge on what type of IT infrastructure or systems are required for their business model to achieve an IT-enabled supply chain. The infrastructure includes the hardware and software and the nature and type of systems required for IT system in a supply chain environment. There are different IT platforms and systems available to enable the application of IT in SCM (Haeckel, 1999) and with proper planning the company should investigate, evaluate and select the IT system and solution most appropriate and fitting towards the company's needs. 


\section{Human factor and people's role}

Supply chain management is built on a foundation of trust and commitment (Lee and Billington, 1992). The consensus is that trust can contribute significantly to the long-term stability of an organization (Heide and John, 1990) and through commitment the partners dedicate resources to sustain and further the goals of the supply chain.

When there is an introduction of a new IT system, people and processes in an organization must undergo a process of significant change, learning, adaptation and growth. As changes of this scale are often drastic and cause intra-organizational tensions (Kuruppuarachchi et al., 2002), human factor must not be neglected when considering successful e-SCM implementation and acceptance. On the contrary, introductory notes and support from top management, technical and practical trainings, open communication, understanding and support are essential to address people's needs and their skepticism in the case of a new IT adoption.

\section{CONCLUSION}

In today's era of communication and technology, it is no longer reasonable nor rational to consider suppliers, customers and partners in isolation as independent entities. The new technologies have enabled integration among the supply chain linking the entire sequence of events and processes in the supply chain into a network of cooperative partners, commonly known as electronic supply chain management. This transformation has broadened the possibilities offered by supply chain management and the dynamics of competitive advantage enabled by an integrated and value adding network of partners. The cooperative ties, extend from end-user customer to the suppliers bonding them to work together to maximize the overall effectiveness of the supply chain in gaining strategic advantage for all involved.

The benefits from such transformation and integration are indispensable. Increased customer satisfaction, reduced lead time, reduced inventory carrying costs, improved and more accurate forecasts, improved communication, improved profits, improved communication and visibility among the supply chain, better customer service, greater competiveness and a strategic asset in achieving corporate objectives and goals. In addition to the benefits, the companies are driven into the adoption of eSCM by the competitive rivalry, global marketplace, increased customer demands and similar external pressures demanding e-business solutions that offer flexibility, agility, richness of information and accessibility in every day operations. 
Lidija Pulevska-Ivanovska, Sasho Josimovski, Kiril Postolov, Neda Kaleshovska

However in spite, the benefits and drivers for adoption of e-SCM, implementing IT in SCM is not an easy task, but rather a challenging project that requires the right team, the right resources, planning, time and support to achieve successful implementation and enjoy the benefits that many companies that have adopted e-SCM are witnessing. To these regards, in this paper the challenges for adopting e-SCM are categorized into three groups: lack of strategic planning and management support; inadequate or incompatible IT systems and human factor as inhibitor in the adoption and implementation. However, with practices, solutions and strategies these challenges can be circumvented and the companies can implement e-SCM and enjoy the benefits from the undertaking and working towards having e-SCM as a strategic advantage.

E-business has a significant effect on supply chain management integration and there is ongoing research on various topics related to eSCM and smoothness of implementation of the same, however as technology advances, so will future research guidelines navigate in these directions into further development in this field, into what more can technology bring to further benefit the supply chain management process and how to efficiently implement these future trends.

\section{LITERATURE}

1. Accenture Poll Finds, (2002). SCM is Key to Improvement, Global Logistics and Supply Chain Strategies, 6(3), p.16

2. Balsmeier, P.W., Voisin, W.J. (1996). Supply Chain Management: a time based stratedgy, Industrial Management, 38(5), p.24

3. Best, M. (1990). The New Competition, Harvard University Press, Cambridge, MA.

4. Beth, C., Burt, D.N., Copacino, W., Gopal, C., Lee H.L., Lynch R.P., Morris S., (2003). Supply chain challenges: building relationships, Harvard Business Review, 81,(7), p.64

5. Biemans, W., Brand, M. (1995), Reverse marketing: a synergy of purchasing and relationship marketing, International Journal of Purchasing and Materials Management, 29-37.

6. Bradley, P., (1999). Managers look to supply chains to cut costs, Logistics Management and Distribuion Report, 38(1), 21-22

7. Cook, R.L., Garver, M.S. (2002). Subscription Supply Chains:the ultimate collaborative paradigm, Mid-American Journal of Business, 17(2), 37-46

8. Cyberlibris, (1999), Retrieved April, 2014 from http://cyberlibris.typepad.com/news/files/dell_case_study.pdf 
9. Durbin, D., Kirshner, T., Retrieved April, 2014 from Ford 2010 profit highest in a decade as sales rise.Bloomberg, Business Week

10. Gimenez, C., Lourenco, H.R., (2008), E-SCM. Internet's impact on Supply Chain Processes, International Journal of Logistics Management,19(30), 309-343, ISSN 0957-4093

11. Graham, G., Hardaker, G., (2000). Supply-chain management across the Internet", International Journal of Physical Distribution \& Logistics Management, 30(3/4), 286-295.

12. Gunasekaren, A., Ngai, E.W.T., (2004). Information Systems in Supply Chain Integration and Management, European Journal of Operational Research, 159(1), 270

13. Haeckel, S.H., (1999). Adaptive Enterprise: Creating and Leading Sense-and-Respond Organizations, Harvard Business, School Press, Boston, MA.

14. Heide, J., John, G. (1990). Consensus and collaboration: norm regulated behavior in industrial marketing relationships, European Journal of Marketing.

15. Kuruppuarachchi, P.R., Mandal, P., Smith, R., (2002). IT project implementation strategies for effective changes: Acritical review. Logistics Information Management, 15(2), 126-137.

16. Lambert, D.M., Cooper C.M., Pagh, D. J., (1998). Supply Chain Management:Implementation Issues and Research Opportunities, The International Journal of Logistics Management, 9(2), p.1

17. Lankford, W.M., (2004). Supply Chain Management and the Internet, Online Information Review, Emerald, 28 (4), 301 - 305.

18. Lee, L. H., Billington, C. (1992). Managing supply chain inventories: pitfalls and opportunities, Sloan Management Review, Spring,. 65-73.

19. Lee, L.H., Whang, D. (2001). E-business and Supply Chain Integration, Stanford Global Supply Chain Management Forum, SGSCMF-W2-2001, p.2

20. McLaren T., Head M., Yuan Y. (2004). Supply chain management information systems capabilities. An exploratory study of electronics manufacturers, Information Systems and e-Business Management, 2 (1), 207-222

21. Mehta, J. (2004). Supply Chain Management in a Global Economy, Total Quality Management, 15(5/6), 841

22. Mentzer, T.J., DeWitt, W., Keebler, S.J., Min, S., Nix, W. N., Smith, D.C., Zacharia, G.Z., (2001). Defining Supply Chain Management, Journal of Business Logistics, .22(2), 3-11 
Lidija Pulevska-Ivanovska, Sasho Josimovski, Kiril Postolov, Neda Kaleshovska

23. Motwani, J., Madan, M., Gunsadekaren, A., (2000). Information Technolodgy in Managing Supply Chains, Logistics Inforamtion Management, 13(5), 320-327

24. Ngai, E.W.T., Chan, E.W.T., (2002). Evaluation of Knowledge Management Tools Using AHP, Expert Systems and Application, 29(4), $889-899$.

25. Poirier, C.C., Bauer, M.J. (2000). E-Supply Chain Management, Berett-Koehler Publishers, Inc, San Francisco

26. Prahalad, C.K., Hamel, G. (1990). The core competence of the corporation, Harvard Business Review, May-June, 79-92.

27. Quinn, J. (1993). The Intelligent Enterprise, The Free Press, New York, NY.

28. Ross, D.F., (2003). Introduction to e-Supply Chain Management, Enabling Technology to Build Market Winning Business Partnerships, St. Lucie Press, Florida.

29. Spekman, E.R., Kamauff JR., W.J., Myhr, N. (1998). An empirical investigation into supply chain management, International Journal of Physical Distribution \& Logistics Management, 28(8), 630-650.

30. USanFranOnline.com, 2012, Retrieved April, 2014 from http://www.usanfranonline.com/resources/supply-chainmanagement/walmart-keys-to-successful-supply-chainmanagement/

31. Watson, R.T., Akelsen, S., Pitt, L.F., (1998). Building mountains in that flat landscape of the World Wide Web, California Management Review, 35-56

Рад је примьен: 26.05.2014. Рад је прихваћен за штампање: 26.06.2014. 